\title{
Conservative Management of Spondylodiscitis after Laparoscopic Sacral Colpopexy: A Case Report and Review of Literature
}

\section{Manejo conservador da espondilodiscite após colpopexia sacral laparoscópica: Relato de caso e revisão da literatura}

\author{
Madalena Andrade Tavares ${ }^{10}$ Ana Rita Silva ${ }^{10}$ Marta Gomes de Melo ${ }^{10}$ Márcia Pacheco ${ }^{2}$ () \\ Nuno Coutinho $^{3(1)}$ Alexandre Ambrósio ${ }^{1(0)}$ Paula Tapadinhas $^{1(0)}$
}

${ }^{1}$ Gynecology and Obstetrics Service, Hospital Vila Franca de Xira,

Address for correspondence Madalena Andrade Tavares, MD, Estrada Lisboa, Portugal

2 Internal Medicine Service, Hospital Vila Franca de Xira, Lisboa, Carlos Lima Costa n 2, 2600-009 Vila Franca de Xira, Portugal Portugal

${ }^{3}$ Orthopedics Service, Hospital Vila Franca de Xira, Lisboa, Portugal (e-mail: madalena.tavares@hvfx.pt).

Rev Bras Ginecol Obstet 2021;43(7):570-577.

\begin{abstract}
Keywords

- spondylodiscitis

- sacral colpopexy

- pelvic organ prolapse

- urogynecological mesh

- discitis

\section{Resumo}

Palavras-chave

- espondilodiscite

- colpopexia sacral

- prolapso de órgãos pélvicos

- tela uroginecológica

- discite
\end{abstract}

Sacral colpopexy is one of the standard procedures to treat apical pelvic organ prolapse. In most cases, a synthetic mesh is used to facilitate the colposuspension. Spondylodiscitis is a rare but potentially serious complication that must be promptly diagnosed and treated, despite the lack of consensus in the management of this complication. We report one case of spondylodiscitis after a laparoscopic supracervical hysterectomy and sacral colpopexy treated conservatively. We also present a literature review regarding this rare complication. A conservative approach without mesh removal may be possible in selected patients (stable, with no vaginal lesions, mesh exposure or severe neurologic compromise). Hemocultures and culture of imageguided biopsies should be performed to direct antibiotic therapy. Conservative versus surgical treatment should be regularly weighted depending on clinical and analytical progression. A multidisciplinary team is of paramount importance in the follow-up of these patients.

A colpopexia sacral é um dos procedimentos padrão para tratar o prolapso de órgãos pélvicos apical. Na maioria dos casos, uma tela sintética é usada para facilitar a colposuspensão. A espondilodiscite é uma complicação rara, mas potencialmente grave, que deve ser prontamente diagnosticada e tratada, apesar da falta de consenso no manejo dessa complicação. Relatamos um caso de espondilodiscite após histerectomia supracervical laparoscópica e colpopexia sacral tratada conservadoramente. Também apresentamos uma revisão da literatura sobre essa complicação rara. Uma abordagem conservadora sem remoção da tela pode ser possível em pacientes received

October 21, 2020

accepted

July 21,2021
DOI https://doi.org/

10.1055/s-0041-1735153. ISSN $0100-7203$.
(C) 2021. Federação Brasileira de Ginecologia e Obstetrícia. All rights reserved.

This is an open access article published by Thieme under the terms of the Creative Commons Attribution License, permitting unrestricted use, distribution, and reproduction so long as the original work is properly cited. (https://creativecommons.org/licenses/by/4.0/)

Thieme Revinter Publicações Ltda., Rua do Matoso 170, Rio de Janeiro, RJ, CEP 20270-135, Brazil 
selecionadas (estáveis, sem lesões vaginais, exposição da tela ou comprometimento neurológico grave). Hemoculturas e cultura de biópsias guiadas por imagem devem ser realizadas para direcionar a antibioticoterapia. O tratamento conservador versus o cirúrgico deve ser avaliado regularmente, dependendo da progressão clínica e analítica. Uma equipe multidisciplinar é de suma importância no acompanhamento desses pacientes.

\section{Introduction}

Pelvic organ prolapse (POP) is the descent of female pelvic organs (vagina, uterus, bladder, and/or rectum) into or through the vagina. It occurs in between 30 and $76 \%$ of women referred to a routine gynecological appointment, ${ }^{1}$ and between 7 and 19\% of them undergo surgical repair. ${ }^{2}$

Sacral colpopexy is the gold standard procedure for apical prolapse correction, also allowing simultaneous correction of other compartment defects. The reported long-term success is between 78 and $100 \%$, with recurrence rates of 0 to $18 \%{ }^{2}$ The procedure can be performed by laparotomy, laparoscopy, or robotic-assisted laparoscopy.

Sacral colpopexy, either abdominal or minimally-invasive, is usually a safe procedure, but may be associated with complications such as mesh erosion (reported in $3.4 \%$ of the cases in abdominal sacral colpopexy and in $2 \%$ in roboticassisted sacral colpopexy), urinary tract infection (10.9\%), hemorrhage and/or blood transfusion (4.4\%), ileus or small bowel obstruction (2.7\%), thromboembolic events (3.3\%), urinary injury $(4.1 \%)$, fistula development, infectious complications (peritonitis, periprosthetic abscess), and spondylodiscitis. $^{3-5}$ Since some of these complications are uncommon, it is difficult to determine the exact prevalence of these events.

Spondylodiscitis is a rare but serious complication of this procedure characterized by the development of an inflammatory process, infectious or not, that involves vertebral bodies and intervertebral discs of the vertebral spine. ${ }^{6}$ It is associated with potentially severe consequences, such as multiple surgeries, prolonged immobilization and hospitalization, neural axis infection, chronic pain, and permanent disability. Considering that the disc space has no direct blood supply, spondylodiscitis develops after hematogenous spread or direct inoculation of microorganisms during invasive spinal surgical procedure. Risk factors for the development of spondylodiscitis, after sacral colpopexy, include infection of other organs (urinary, vaginal, oral, respiratory, and gastrointestinal) and vaginal mesh exposure. ${ }^{7}$ Its clinical presentation varies from indolent with no fever to high fever, back pain, mobility limitation, pain radiation to the lower extremities, and vaginal discharge. ${ }^{8}$

Most of the reported cases of spondylodiscitis after sacral colpopexy required at least one surgical procedure during the treatment of this complication. ${ }^{8}$

We present a case of spondylodiscitis after a laparoscopic supracervical hysterectomy and sacral colpopexy that was treated conservatively with antimicrobial agents. This approach avoided a second surgical procedure with removal of the mesh and eventual recurrence of her prolapse. In addition, we reviewed the literature concerning this type of complication after a sacral colpopexy. We revised the most common surgical route used, types of sutures and meshes, how long after the primary surgery the spondylodiscitis manifested, and if there were any previous infectious episodes associated. Our research also included the type of microorganisms detected in culture samples that could alter the antibiotic therapy normally used in other types of spondylodiscitis.

\section{Case Report}

A 65-year-old multiparous woman with a previous history of type II diabetes mellitus, hypertension, dyslipidemia, bilateral gonarthrosis and gouty arthropathy was referred to our hospital due to complaints of POP. A physical examination revealed a stage 3 prolapse with uterine leading edge according to the POP Quantification system (POP-Q), ${ }^{9}$ and she underwent a laparoscopic supracervical hysterectomy with bilateral salpingo-oophorectomy and sacral colpopexy. A nonabsorbable prolene soft mesh (Gynecare Gynemesh(ETHICON, LLC, San Lorenzo, Porto Rico)) was attached to the anterior and posterior vaginal walls (one suture anteriorly and two sutures posteriorly) and to the sacral promontory (one suture) using a sterile nonabsorbable braided polyester surgical suture (Ethibond Excel, ETHICON, Inc., Somerville, NJ, USA). At the level of the levator ani muscle, a sterile absorbable polydioxanone monofilament suture (PDS II 2/0 - ETHICON, Inc., Somerville, NJ, USA) was used. The mesh was peritonealized using an absorbable synthetic polyglactin braided suture (VICRYL 1/0 ETHICON, Inc., Somerville, NJ, USA). Intravenous cefazolin (2 g) was administered as perioperative antimicrobial prophylaxis. The surgery and the immediate postoperative period were uneventful.

One month after the surgery, the patient presented to the emergency department with complaints of lumbosacral minor pain. She was hemodynamically stable and apyretic. Her urine analysis was positive for leucocytes and proteins, and oral antibiotic ambulatory treatment (amoxicillin/clavulanic acid, according to national guidelines for uncomplicated urinary tract infection $)^{10}$ was prescribed. Three months postoperatively, the patient was readmitted with progressive and intense lumbosacral pain radiating to both lower limbs and severe gait limitation. She denied fever, vaginal bleeding, vaginal discharge, urinary complaints, or abdominal pain. The patient was afebrile and her physical examination, including the gynecological exam, showed no abnormalities. There was no evidence of vaginal lesions or mesh exposure. Her blood tests revealed an elevated C-reactive protein (CRP 

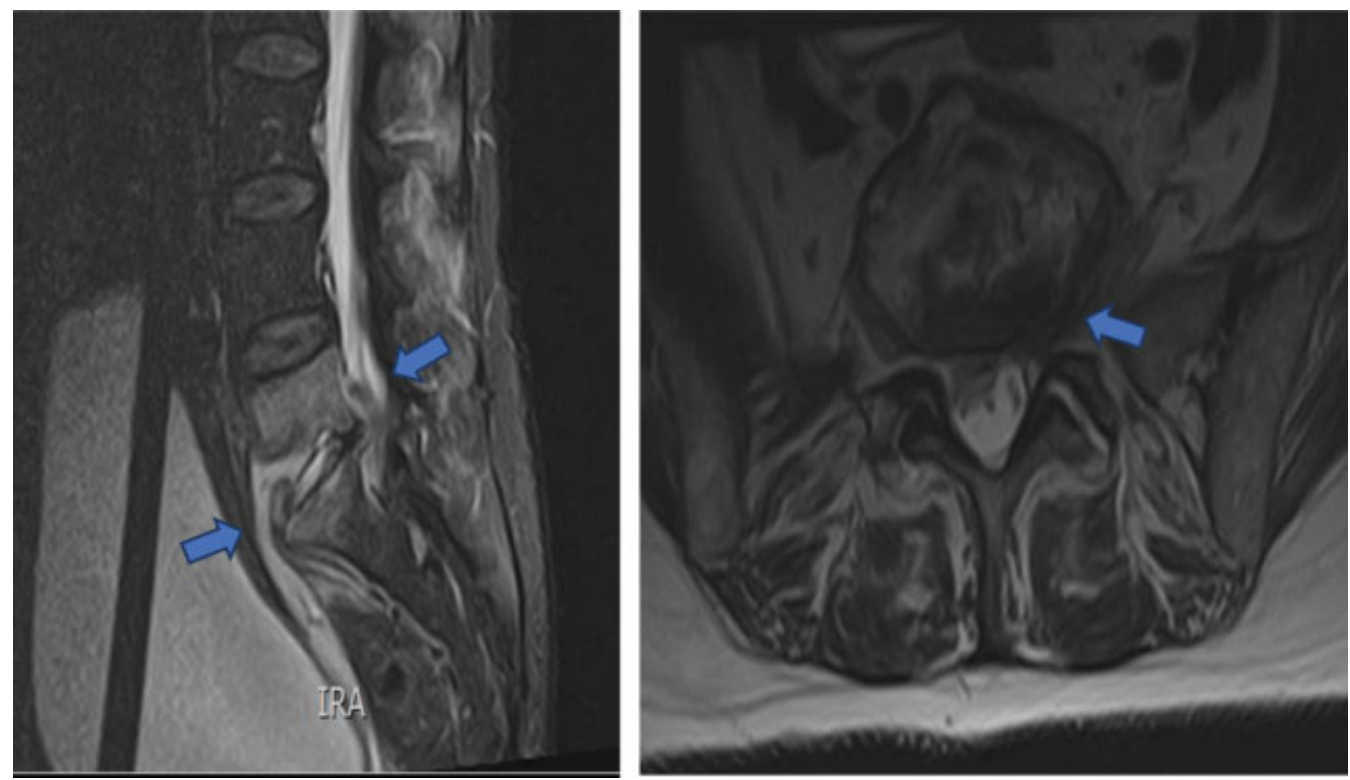

Fig. 1 Magnetic resonance imaging before treatment-Accentuated edema of the somatic L 5 and S1 sponge with erosive anomalies in the vertebral plates, suggestive of spondylodiscitis. Associated phlegmon with anterior extension to the sacrum and to the posterior peridural region.

$9.51 \mathrm{mg} / \mathrm{dL}$ ) with a normal white cell count. The remaining blood tests were unremarkable. Her blood, vaginal (including for bacterial vaginosis), and urine cultures did not reveal any atypical or overwhelming microbial growth. A computed tomography (CT) exam showed an anterior interruption of the bone cortical in L5 and S1 with inflammatory reaction involving the intervertebral disc.

A magnetic resonance imaging (MRI) exam revealed an accentuated edema of the somatic L5 and S1 sponge with erosive anomalies in the vertebral plates of these vertebrae, suggestive of spondylodiscitis with associated phlegmon with anterior extension to the sacrum and to the posterior peridural region (-Fig. $\mathbf{1}$ ).

After multidisciplinary discussion (internal medicine, gynecology and orthopedics), the most likely diagnosis of spondylodiscitis after sacral colpopexy was assumed and a conservative management was implemented (broad-spectrum intravenous antibiotic therapy and physiotherapy).

The patient fulfilled 6 days of intravenous empiric therapy with vancomycin and ceftriaxone (according to international guidelines regarding vertebral osteomyelitis) $)^{11}$ and then, after discussion with the infectious diseases consultant, continued with 19 days of intravenous amoxicillin and clavulanic acid (to cover anaerobic agents, including Bacterioides spp.), with progressive clinical (pain, gait) and analytical (CRP $1.11 \mathrm{mg} / \mathrm{dL}$ at discharge) improvement. The MRI findings on the $18^{\text {th }}$ day of hospitalization remained stable and without neurologic involvement.

The patient was discharged on the $25^{\text {th }}$ day of hospitalization, without requiring analgesic medication and medicated with amoxicillin and clavulanic acid per os (until completing a total of 6 weeks of antibiotic therapy with amoxicillin and clavulanic acid) (-Tables 1 and 2).

Twenty-four months postsurgery, the patient demonstrated a favorable improvement with minor lumbosacral pain radiating to both proximal lower limbs without needing analgesic medication and with unlimited mobility. An MRI exam revealed resolution of the inflammatory peridural component with postinfection ankylosis signs of L5-S1 (-Fig. 2). There was no recurrence of the POP. The patient

Table 1 Characteristics before complication

\begin{tabular}{ll}
\hline Characteristic & Data \\
\hline Mean age in years (range) & $60(41-81)$ \\
Surgical route, $\mathrm{n}(\%)$ & $19(36.5)$ \\
Laparotomic & $23(44.2)$ \\
Laparoscopic & $8(15.4)$ \\
Robotic-assisted laparoscopy & $2(3.8)$ \\
Not reported & \\
Concomitant Procedures, $\mathrm{n}(\%)$ & $13(25)$ \\
Total hysterectomy & $12(23)$ \\
Supracervical hysterectomy & $(17.3)$ \\
Salpingo-oophorectomy & $7(13.5)$ \\
Rectopexy & $3(5.8)$ \\
Burch procedure & \\
Sacral anchorage, $\mathrm{n}$ (\%) & $28(53.9)$ \\
Synthetic mesh & $4(7.7)$ \\
Strips & $4(7.7)$ \\
Partially absorbable & $1(1.9)$ \\
Biological mesh & $2(3.8)$ \\
Direct sutures & $13(25)$ \\
Unknown & \\
Attachment to the promontory, $\mathrm{n}(\%)$ & $19(36.5)$ \\
Nonabsorbable sutures & $12(23.1)$ \\
Staples, clips, tacks, or screws & $21(40.4)$ \\
Unknown &
\end{tabular}


Table 2 Characteristics of the complication

\begin{tabular}{ll}
\hline Characteristic & Data \\
\hline Mean time to presentation (range) & 12 months \\
& $(2$ days - 8 years) \\
Initial infection or complication, $\mathrm{n}(\%)$ & \\
Urinary infection & $9(17.3)$ \\
Dental infection & $1(1.9)$ \\
Isolated vaginal discharge & $2(3.8)$ \\
Isolated vaginitis & $3(5.8)$ \\
Vaginal mesh exposure & $2(3.8)$ \\
Vaginal symptoms with vaginal mesh & $7(13.6)$ \\
exposure or vaginal lesion & $1(1.9)$ \\
Small bowel obstruction & $1(1.9)$ \\
Sigmoid diverticulitis & $1(1.9)$ \\
Fistula development & $25(48.1)$ \\
Not reported & \\
Microbiological analysis, $n$ (\%) & $8(15.4)$ \\
Not reported & $7(13.6)$ \\
Performed and negative & $37(71)$ \\
Performed and positive & \\
Management, $n$ (\%) & $13(25)$ \\
Antibiotic treatment alone & $37(71)$ \\
Antibiotic and surgical treatment & \\
Unknown & \\
\hline
\end{tabular}

provided informed consent for the publication of the present case and accompanying images.

\section{Discussion}

\section{Case Discussion}

According to the literature, pyogenic spondylodiscitis can be treated with antibiotics in between 50 and $75 \%$ of the cases. ${ }^{12}$
However, there is little evidence about the correct management of pyogenic spondylodiscitis after abdominal surgery. Staphylococcus spp. and Streptococcus spp. are the main responsible microorganisms in 50\% of all pyogenic spondylodiscitis cases, followed by gram-negative bacilli; therefore, antibiotic therapy with vancomycin and a third- or fourthgeneration cephalosporin are usually administered empirically until the results of microbiology are available. ${ }^{11}$ The ideal total duration of antibiotic therapy is not well-defined, with some guidelines recommending 6 weeks of total antibiotic therapy (intravenous and oral) with careful review to determine if further treatment is required. ${ }^{11,13}$ Other centers recommend intravenous antibiotics for 4 to 6 weeks or until normalization of CPR levels, followed by oral antibiotics until a total of 3 months of treatment. ${ }^{12}$

The risks and benefits of surgery should be weighted and adapted to the general status, comorbidities, and response to antibiotic treatment of the patient. Surgery is definitely indicated in case of neural compression, neurologic deficit, progressive deformation or instability or in case of medical treatment failure. ${ }^{7,14}$ Surgical treatment often includes mesh removal and/or other orthopedic procedures (laminectomy, discectomy etc).

Although some authors recommend an additional surgery for mesh removal as soon as the diagnosis of spondylodiscitis after sacral colpopexy is confirmed, ${ }^{15}$ we opted for a different approach. As our patient did not present severe systemic or neurological symptoms, mesh exposure or vaginal lesions and considering that it was a clean surgery (supracervical hysterectomy without entering the vagina), we decided to initiate a conservative treatment with daily close surveillance. The patient was treated as an inpatient during the 25 days of intravenous antibiotic therapy, which allowed progressive recovery (clinical and analytical) and reinforced the decision of maintaining the conservative treatment. The patient was discharged when her CRP was almost negative and when she became independent from intravenous analgesia.
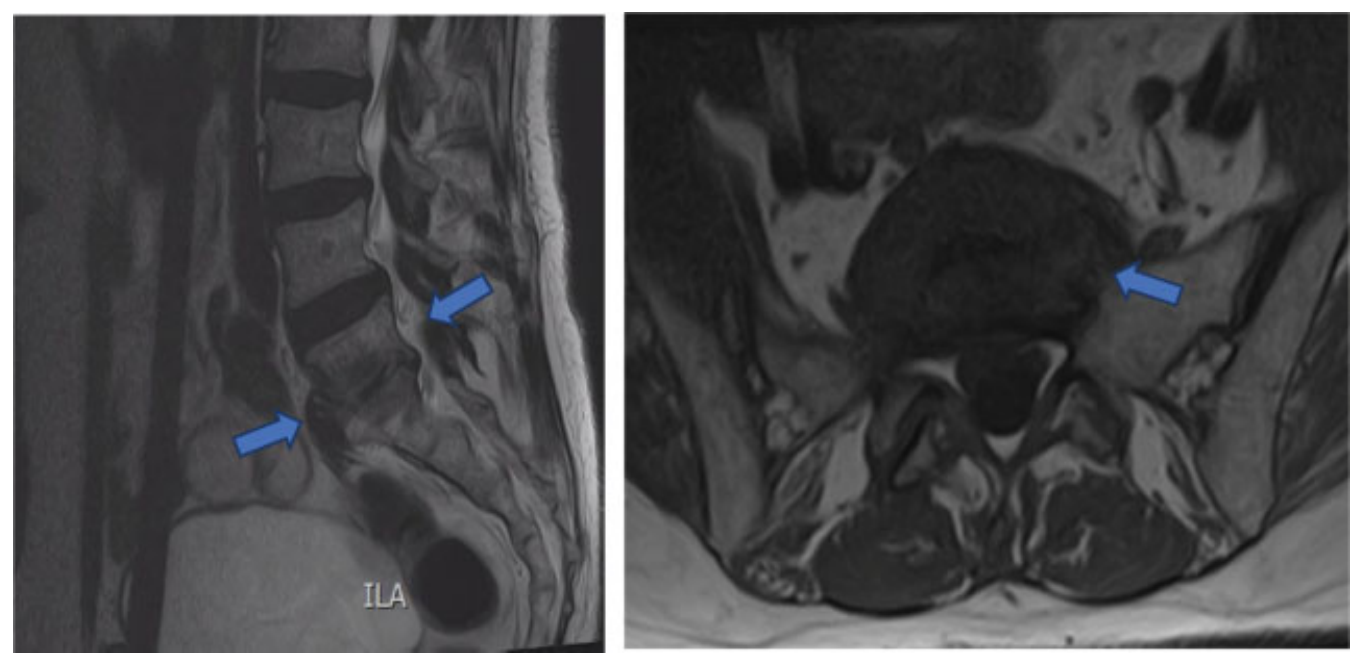

Fig. 2 Magnetic resonance imaging after treatment - Resolution of the inflammatory peridural component with post-infection ankylosis signs of L5-S1. 
Even though microbiological cultures (vaginal, urinary, and hematologic) were negative, we verified that, with empirical antibiotic treatment, there was a favorable clinical, analytical and imaging evolution, dismissing the need for a second surgical intervention with eventual mesh removal. This required a close follow-up but without recurrence of pelvic organ prolapse, which was not evaluated in most of the other reports.

However, it would have been recommended to perform an image-guided aspiration or biopsy to establish the exact microorganism causing this complication. Image-guided aspiration or biopsy or intraoperative samples of the infected region remain a very important diagnostic tool that allows pathogen-directed therapy. ${ }^{11}$

It is also important to notice that event though permanent braided sutures may be associated with increased infectious risk, these sutures provide greater knot security than monofilament sutures, which, in this type of surgery, reduce the risk of mesh detachment and recurrent prolapsus.

\section{Literature Review}

We performed a PubMed search of the literature on October 4, 2020, using the following terms: spondylodiscitis, discitis, osteomyelitis, pyogenic spondylodiscitis, pyogenic discitis, pyogenic osteomyelitis or vertebral osteomyelitis and sacral colpopexy, pelvic organ prolapse or promontofixation. Additionally, the references of all articles included were confirmed for further information and eventual description of other cases.

Data extraction from PubMed provided a total of 36 abstracts, and further reference search yielded additional 8 articles, gathering a total of 52 cases, ${ }^{6-8,14-52}$ including ours. The summary of the results is presented in -Tables $\mathbf{1}$ and $\mathbf{2}$. The list of all studied cases with their detailed characteristics is presented in the - Supplementary Table S1 (available online).

In the reported cases of spondylodiscitis after sacral colpopexy, the surgical route was laparotomic in $36.5 \%$, laparoscopic in $44.2 \%$, and robotic-assisted laparoscopy in $15.4 \%$. Sacral anchorage was performed with synthetic mesh (nonabsorbable or partially absorbable) or strip in the majority of the cases (63.5\%). Biologic meshes and direct sutures were used in 1.9 and $3.8 \%$ of the surgeries, respectively. In $25 \%$ of all cases, the type of sacral anchorage was not specified. The attachment to the promontory was made with sutures in $36.5 \%$ (all nonabsorbable sutures) and with staples, clips, tacks or screws in $23 \%$ of the cases. In $40.4 \%$ of the cases, information about attachment was lacking.

There is still debate regarding the best mesh and suture material to use, but, as observed, nonabsorbable material is the most frequently used, with better results in terms of prolapse resolution. $^{53}$

The time between surgery and clinical presentation of spondylodiscitis ranged from a few days after surgery up to 8 years, but the majority presented with symptoms $<5$ months after surgery (75\%).

Spondylodiscitis was preceded by a documented infection or other complication in 52\% of the cases. Previous urinary or dental infection was reported in $19.2 \%$ of the cases. Isolated vaginal discharge or vaginitis were reported in $9.6 \%$, while mesh erosion without vaginal symptoms occurred in $3.8 \%$ of the cases. In $13.5 \%$ of the reported cases, there was a combination of vaginal symptoms (vaginitis/vaginal discharge) with vaginal mesh exposure or vaginal lesion (vaginal ulcer/vaginal apex opening) - in one of these cases, there was a concomitant urinary tract infection and, in another case, small bowel obstruction was reported. Urinary tract infection as a previous infection occurred more frequently in women who underwent supracervical hysterectomy ( 5 cases in 23 hysterectomies) than in those who underwent total hysterectomy ( 0 cases in 25 total hysterectomies). On the other hand, vaginal symptoms and mesh exposure seem to occur more frequently in total hysterectomies (6 in 25 hysterectomies versus 1 in 23 supracervical hysterectomies).

Other events that preceded the presentation of spondylodiscitis were: small bowel obstruction (two cases - one of them in association with vaginal discharge and mesh erosion), sigmoid diverticulitis (one case), and a fistula development from rectopexy to the anterior vertebral ligament (one case).

In 44 of the 52 studied cases, there were reports on the microbiological analysis of collected samples (blood, urine, vaginal, image-guided biopsies/aspirations of infection site, surgical samples of the mesh or the surrounding tissue). Of these, $13.5 \%(n=7)$ had negative cultures. From the 44 cases that reported microbiological analysis, a single microorganism was found in $47.7 \%(n=21)$, and polymicrobial infections were present in $36.4 \%(n=16)$.

The most prevalent microorganism detected were: Bacteroides spp. (19.2\%), Staphylococcus aureus (15.4\%), Escherichia coli (15.4\%), and Enterococcus spp. (13.5\%). The prevalence of infections related to Streptococcus spp. and Staphylococcus spp. was $32.7 \%$.

In 15 cases, there was information about peripherical cultures (blood, urine, and vaginal swab), documenting 2 negative and 13 positive cases. In this type of microbiological culture (31\% polymicrobial infections), the most prevalent microorganisms detected were: Bacteroides spp. (38.5\%) followed, in equal prevalence of $31 \%$ by $S$. aureus, E. coli and Streptococcus spp.

Regarding cultures from the infection site or local cultures (image-guided biopsies/aspirations or intraoperative samples including mesh culture), the review revealed 6 negative and 33 positive cultures. In the positive cultures group, $S$. aureus was the most prevalent microorganism (21\%), followed by Bacteroides spp. (18\%), Enterococcus spp. (15\%) and Pseudomonas aeruginosa (15\%). The prevalence of infections related to Streptococcus spp. and/or Staphylococcus spp. was $46 \%$ in peripherical cultures and $39 \%$ in cultures from the infection site.

Unfortunately, cultures from the infection site are not always consistent with peripherical cultures. From all the positive peripherical cultures, only in $62 \%$ ( 8 cases) the microorganism detected was the same as in the culture from the infection site ( 7 cases of positive hemocultures and 1 case of positive uroculture). Even for positive hemocultures, 36\% did 
not correspond to the same microorganism of the local culture. Therefore, although peripherical cultures (mainly hemocultures) are strongly recommended to detect all possible microorganisms responsible for this infection, they will not be enough to narrow the empirical antibiotic therapy. The most recommended diagnostic tool for microorganism detection is image-guided biopsy/aspiration or culture from intraoperative samples.

During our review, we noticed that the prevalence of infections due to Streptococcus spp. and Staphylococcus spp. as a group was lower than the one reported in the literature for pyogenic spondylodiscitis (50\%), and other microorganisms such as Bacteroides spp., E. coli and Enterococcus spp. had a relevant prevalence. This emphasizes the paramount importance of sample collection for microbiological analysis and antibiotic therapy decision and of the need to include anaerobe coverage if an empirical antibiotic therapy is started.

In addition to our case, the research revealed 12 cases that were treated only with antibiotics. In 11 of these cases, there was a positive hemoculture or site infection culture (in 1 case there is no information about cultures), with Bacteroides spp., S. aureus and $P$. aeruginosa being the most common pathogens identified. The type of antibiotic treatment in this group was heterogenous, and its duration varied from 4 weeks up to 6 months ( 4 weeks in $9 \%$; 8 to 12 weeks in $64 \%$; and $>12$ weeks in $27 \%$ of the patients).

Most cases of surgical treatment (performed in 37 cases) involved mesh or bone anchors removal ( $81 \%$ of all cases treated surgically; $57.7 \%$ of all reported cases). Other common associated procedures were discectomy, laminectomy, and abscess debridement. In some cases, the patient underwent $>1$ surgery to treat the complication. The duration of the antibacterial treatment in surgically treated patients was not always revealed (only in $43.6 \%$ of the cases). In the described cases, it was maintained for 2 to 14 weeks (< 6 weeks in $23.5 \%$; 6 to 8 weeks in $35.3 \%$; 8 to 12 weeks in $17.7 \%$; and $>12$ weeks in $23.5 \%$ of the patients), while antifungal therapy was prolonged for 12 months in 1 patient.

Recommendations to prevent spondylodiscitis associated with sacral colpopexy have been suggested. During this procedure, the step of fixation of the mesh to the sacral promontory (defined as the most superior point on the anterior surface of S1) is of paramount importance not only for diminishing the risk of hemorrhage but also to avoid making a very deep stitch or risking incorrect location. ${ }^{54}$

The suture should be attached to the anterior longitudinal ligament keeping in mind that its maximum thickness is $2 \mathrm{~mm}$. Additionally, it is of utmost relevance to avoid placing the suture in the region of the disc space. To achieve this, the surgeon should directly visualize the ligament as well as palpate the hard-bony part instead of the spongy disc (easier at laparotomy than in minimally invasive procedures). Good et al. ${ }^{54}$ reported the existence, in the supine position, of an acute angle of descent (average $60^{\circ}$ ) between the anterior surfaces of L5 and S1. Consequently, the most prominent structure in the presacral space is the L5-S1 disc and not the "true" sacral promontory. Thereby, if the surgeon does not acknowledge this fact, it is not infrequent for the mesh to be attached to the intervertebral disc. ${ }^{54}$

\section{Conclusion}

We analyzed 52 cases of spondylodiscitis after sacral colpopexy. Being a rare complication of sacral colpopexy, there should be a high index of suspicion for spondylodiscitis after this type of procedure. In $52 \%$ of the cases, there was a previous documented infection (mainly vaginal or urinary) or other complication (mesh exposure), and these patients should be followed-up closely to precociously detect this possible complication. Back pain associated with elevated CRP after this procedure should lead us to further investigation to achieve a prompt diagnosis and initiate adequate treatment. A conservative approach without mesh removal may be possible with vigilant attention. However, hemocultures and image-guided biopsy/aspiration of the infection site should not be neglected, since the microorganisms causing this complication may be different from the typical Staphylococcus spp. and Streptococcus spp. responsible for $50 \%$ of other types of spondylodiscitis. If empirical treatment is prescribed, it should also cover anaerobe, to cover for Bacteroides spp., which is one of the most common microorganisms detected in this complication. The patient should be admitted for attentive surveillance and intravenous antibiotic therapy and analgesia. The authors recommend conservative treatment in stable patients without vaginal mesh exposure, vaginal lesion, neural compression, neurologic deficit, progressive deformation, or instability. If there is a favorable recovery of clinical symptoms and analytical parameters, conservative treatment should be maintained with prolonged antibiotic therapy for at least 6 weeks. On the other hand, neurological aggravation or conservative treatment failure should redirect the approach for a surgical treatment. It is also of paramount importance that a multidisciplinary team is implicated in the follow-up of these patients.

Conflict of Interests

The authors have no conflict of interests to declare.

\section{References}

1 Barber MD. Pelvic organ prolapse. BMJ. 2016;354:i3853. Doi: 10.1136/bmj.i3853

2 Nygaard I, Brubaker L, Zyczynski HM, Cundiff G, Richter H, Gantz $\mathrm{M}$, et al. Long-term outcomes following abdominal sacrocolpopexy for pelvic organ prolapse. JAMA. 2013;309(19):2016-2024. Doi: $10.1001 /$ jama.2013.4919

3 Campos S, Billone V, Durão M, et al. Complications of laparoscopic sacropexy: as harmless as they seem? Acta Obstet Ginecol Port. 2016;10(01):21-31

4 Matthews CA. Minimally invasive sacrocolpopexy: how to avoid short- and long-term complications. Curr Urol Rep.. 2016;17 (11:81:1-7. Doi: 10.1007/s11934-016-0638-7

5 Nygaard IE, McCreery R, Brubaker L, et al; Pelvic Floor Disorders Network. Abdominal sacrocolpopexy: a comprehensive review. Obstet Gynecol. 2004;104(04):805-823. Doi: 10.1097/01. AOG.0000139514.90897.07

6 Api M, Kayatas S, Boza A. Spondylodiscitis following sacral colpopexy procedure: is it an infection or graft rejection? Eur J 
Obstet Gynecol Reprod Biol. 2015;194:43-48. Doi: 10.1016/j. ejogrb.2015.08.003

7 Propst K, Tunitsky-Bitton E, Schimpf MO, Ridgeway B. Pyogenic spondylodiscitis associatedwith sacral colpopexy and rectopexy: report of two cases and evaluation of the literature. Int Urogynecol J. 2014;25(01):21-31. Doi: 10.1007/s00192-0132138-3

8 Müller PC, Berchtold C, Kuemmerli C, Ruzza C, Z'Graggen K, Steinemann DC. Spondylodiscitis after minimally invasive rectoand colpo-sacropexy: Report of a case and systematic review of the literature. J Minim Access Surg. 2020;16(01):5-12. Doi: 10.4103/jmas.JMAS_235_18

9 Haylen BT, Maher CF, Barber MD, Camargo S, Dandolu V, Digesu A, et al. An International Urogynecological Association (IUGA) / International Continence Society (ICS) joint report on the terminology for female pelvic organ prolapse (POP). Int Urogynecol J. 2016;27(02):165-194. Doi: 10.1007/s00192-015-2932-1

10 Paiva JA, Sá AB, Froes F, et al. Norma da Direção geral de saúde: Terapêutica de infeções do aparelho urinário: Norma DGS 015/2011 [Internet]. 2011 [cited 2021 Jan 12]. Available from: http://nocs.pt/wp-content/uploads/2015/11/Terapêutica-deinfeções-do-aparelho-urinário-comunidade.pdf

11 Berbari EF, Kanj SS, Kowalski TJ, Darouiche RO, Widmer AF, Schmitt SK, et al; Infectious Diseases Society of America. 2015 Infectious Diseases Society of America (IDSA) clinical practice guidelines for the diagnosis and treatment of native vertebral osteomyelitis in adults. Clin Infect Dis. 2015;61(06):e26-e46. Doi: $10.1093 / \mathrm{cid} / \mathrm{civ} 482$

12 Cheung WY, Luk KD. Pyogenic spondylitis. Int Orthop. 2012;36 (02):397-404. Doi: 10.1007/s00264-011-1384-6

13 Bernard L, Dinh A, Ghout I, Simo D, Zeller V, Issartel B, et al; Duration of Treatment for Spondylodiscitis (DTS) study group. Antibiotic treatment for 6 weeks versus 12 weeks in patients with pyogenic vertebral osteomyelitis: an open-label, non-inferiority, randomised, controlled trial. Lancet. 2015;385(9971):875-882. Doi: 10.1016/S0140-6736(14)61233-2

14 Jenson MD AV, Scranton R, Antosh DD, Simpson RK. Lumbosacral osteomyelitis and discitis with phlegmon following laparoscopic sacral colpopexy. Cureus. 2016;8(07:e671:1-8. Doi: 10.7759/ cureus.671

15 Gungor Ugurlucan F, Yasa C, Demir O, Basaran S, Bakir B, Yalcin O. Long-term follow-up of a patient with spondylodiscitis after laparoscopic sacrocolpopexy: an unusual complication with a review of the literature. Urol Int. 2019;103(03):364-368. Doi: $10.1159 / 000494370$

16 Qu DC, Chen HB, Yang MM, Zhou HG. Management of lumbar spondylodiscitis developing after laparoscopic sacrohysteropexy with a mesh: A case report and review of the literature. Medicine (Baltimore). 2019;98(49:e18252:1-7. Doi: 10.1097/ MD.0000000000018252

17 Miksić NG, Kljaić Dujić M, Rejc Marko J, Voršič M, But I. Bacteroides fragilis sacral spondylodiscitis and epidural abscess after sacrocolpopexy: a case report and literature review. J Int Med Res. 2019;47(09):4568-4574. Doi: 10.1177/0300060519866270

18 Sato H, Teramoto S, Sato K, Abe H. Surgical management of mesh infection following laparoscopic sacrocolpopexy and tensionfree vaginal mesh surgery: a report of two cases with a literature review. IJU Case Rep. 2018;2(01):54-56. Doi: 10.1002/ iju5.12039

19 Boyd B, Pratt T, Mishra K. Fungal lumbosacral osteomyelitis after robotic-assisted laparoscopic sacrocolpopexy. Female Pelvic Med Reconstr Surg. 2018;24(06):e46-e48. Doi: 10.1097/ SPV.0000000000000612

20 Gupta P, Ehlert M, Bartley J, Gilleran J, Killinger KA, Boura JA, et al. Perioperative outcomes, complications, and efficacy of roboticassisted prolapse repair: a single institution study of 196 patients. Female Pelvic Med Reconstr Surg. 2018;24(06):408-411. Doi: $10.1097 /$ SPV.0000000000000472
21 Pasquer A, Djeudji F, Pechoux A, Barth X. Spondylodiscitis after rectopexy: diagnostic of a rare complication. Tech Coloproctol. 2017;21(01):63-64. Doi: 10.1007/s10151-016-1566-8

22 Feng TS, Thum DJ, Anger JT, Eilber KS. Sacral osteomyelitis after robotic sacrocolpopexy. Female Pelvic Med Reconstr Surg. 2016; 22(01):e6-e7. Doi: 10.1097/SPV.0000000000000219

23 Núñez-Pereira S, Huhmann NV, Rheinwalt KP, Bullmann V. Lumbosacral spondylodiscitis due to rectal fistula following mesh penetration 7 years after colpopexy. Int J Surg Case Rep. 2016; 24:219-222. Doi: 10.1016/j.ijscr.2016.04.047

24 Brito LG, Giraudet G, Lucot JP, Cosson M. Spondylodiscitis after sacrocolpopexy. Eur J Obstet Gynecol Reprod Biol. 2015;187:72. Doi: 10.1016/j.ejogrb.2015.02.024

25 Tymchak ZA, Epp A, Fourney DR. Lumbosacral discitis-osteomyelitis after mesh abdominosacrocolpopexy. Spine J. 2015;15(01): 194-195. Doi: 10.1016/j.spinee.2014.08.004

26 Vujovic Z, Cuarana E, Campbell KL, Valentine N, Koch S, Ziyaie D. Lumbosacral discitis following laparoscopic ventral mesh rectopexy: a rare but potentially serious complication. Tech Coloproctol. 2015;19(04):263-265. Doi: 10.1007/s10151-015-1279-4

27 Kdous M, Elhouda Kraiem N, Zhioua F, Ferchiou M. Pyogenic spondylodiscitis after laparoscopic sacral colpopexy with staples. Gynécol Obstét Fertil. 2015;43(06):478-480. Doi: 10.1016/j. gyobfe.2015.03.013

28 Arsene E, Giraudet G, Lucot JP, Rubod C, Cosson M. Sacral colpopexy: long-term mesh complications requiring reoperation (s). Int Urogynecol J. 2015;26(03):353-358. Doi: 10.1007/s00192-0142514-7

29 Probst P, Knoll SN, Breitenstein S, Karrer U. Vertebral discitis after laparoscopic resection rectopexy: a rare differential diagnosis. J Surg Case Rep. 2014;2014(08):rju075. Doi: 10.1093/jscr/rju075

30 Anand M, Tanouye SL, Gebhart JB. Vesicosacrofistulization after robotically assisted laparoscopic sacrocolpopexy. Female Pelvic Med Reconstr Surg. 2014;20(03):180-183. Doi: 10.1097/ SPV.0000000000000033

31 Apostolis CA, Heiselman C. Sacral osteomyelitis after laparoscopic sacral colpopexy performed after a recent dental extraction: a case report. Female Pelvic Med Reconstr Surg. 2014;20(06): e5-e7. Doi: 10.1097/SPV.0000000000000092

32 Roth TM, Reight I. Laparoscopic mesh explantation and drainage of sacral abscess remote from transvaginal excision of exposed sacral colpopexy mesh. Int Urogynecol J. 2012;23(07):953-955. Doi: 10.1007/s00192-011-1630-x

33 Voelker A, Hoeckel M, Heyde CE. Lumbosacral spondylodiscitis after sacral colpopexy of a sigmoid neovagina in a patient with vaginal melanoma. Surg Infect (Larchmt). 2012;13(02):134-135. Doi: $10.1089 /$ sur.2011.083

34 Rajamaheswari N, Agarwal S, Seethalakshmi K. Lumbosacral spondylodiscitis: an unusual complication of abdominal sacrocolpopexy. Int Urogynecol J. 2012;23(03):375-377. Doi: 10.1007/ s00192-011-1547-4

35 Grimes CL, Tan-Kim J, Garfin SR, Nager CW. Sacral colpopexy followed by refractory Candida albicans osteomyelitis and discitis requiring extensive spinal surgery. Obstet Gynecol. 2012;120(2 Pt 2):464-468. Doi: 10.1097/AOG.0b013e318256989e

36 Draaisma WA, van Eijck MM, Vos J, Consten EC. Lumbar discitis after laparoscopic ventral rectopexy for rectal prolapse. Int J Colorectal Dis. 2011;26(02):255-256. Doi: 10.1007/s00384010-0971-0

37 Collins SA, Tulikangas PK, LaSala CA, Lind LR. Complex sacral abscess 8 years after abdominal sacral colpopexy. Obstet Gynecol. 2011;118 (2 Pt 2):451-454. Doi: 10.1097/AOG.0b013e3182234e7c

38 Muffly TM, Diwadkar GB, Paraiso MF. Lumbosacral osteomyelitis after robot-assisted total laparoscopic hysterectomy and sacral colpopexy. Int Urogynecol J. 2010;21(12):1569-1571. Doi: $10.1007 / \mathrm{s} 00192-010-1187-0$

39 Dalwai R, Menon KV, Kumar RJ. Pyogenic diskitis of the L5-S1 disk space following inadvertent placement of a sacrocolpopexy 
screw. Int J Gynaecol Obstet. 2010;111(03):268-269. Doi: 10.1016/j.ijgo.2010.07.012

40 Nosseir SB, Kim YH, Lind LR, Winkler HA. Sacral osteomyelitis after robotically assisted laparoscopic sacral colpopexy. Obstet Gynecol. 2010;116(Suppl 2):513-515. Doi: 10.1097/AOG.0b013e3181e10ea6

41 Descargues G, Bouzouita A, Grise P. [Infectious spondylodiscitis after a laparoscopic sacrocolpopexy: about one case]. Gynécol Obstét Fertil. 2009;37(02):183-185. Doi: 10.1016/j. gyobfe.2008.11.013

42 Downing KT. Vertebral osteomyelitis and epidural abscess after laparoscopic uterus-preserving cervicosacropexy. J Minim Invasive Gynecol. 2008;15(03):370-372. Doi: 10.1016/j. jmig.2007.12.006

43 Taylor GB, Moore RD, Miklos JR. Osteomyelitis secondary to sacral colpopexy mesh erosion requiring laminectomy. Obstet Gynecol. 2006;107(2 Pt 2):475-477. Doi: 10.1097/01. AOG.0000187949.87223.06

44 Hart SR, Weiser EB. Abdominal sacral colpopexy mesh erosion resulting in a sinus tract formation and sacral abscess. Obstet Gynecol. 2004;103(5 Pt 2):1037-1040. Doi: 10.1097/01. AOG.0000121829.55491.0d

45 Salman MM, Hancock AL, Hussein AA, Hartwell R. Lumbosacral spondylodiscitis: an unreported complication of sacrocolpopexy using mesh. BJOG. 2003;110(05):537-538. Doi: 10.1046/j.14710528.2003.02012.X

46 Beloosesky Y, Grinblat J, Dekel A, Rabinerson D. Vertebral osteomyelitis after abdominal colposacropexy. Acta Obstet Gynecol Scand. 2002;81(06):567-568. Doi: 10.1034/j.16000412.2002.810617.x
47 Kapoor B, Toms A, Hooper P, Fraser AM, C WF M Cox. Infective lumbar discitis following laparascopic sacrocolpopexy. J R Coll Surg Edinb. 2002;47(05):709-710

48 Cosson M, Narducci F, Querleu D, Crépin G. [Experimental use of laparoscopic material: report of a case of spondylodiscitis after laparoscopic sacropexy with Taker]. Ann Chir. 2001;126(06):554-556. Doi: 10.1016/S0003-3944(01)005545 French

49 Gertzbein SD, Hollopeter M, Bertini JE Jr, Murdock HD. An unusual cause of lumbar discitis. Spine (Phila Pa 1976). 1998;23(06): 734-736. Doi: 10.1097/00007632-199803150-00017

50 Weidner AC, Cundiff GW, Harris RL, Addison WA. Sacral osteomyelitis: an unusual complication of abdominal sacral colpopexy. Obstet Gynecol. 1997;90(4 Pt 2):689-691. Doi: 10.1016/s00297844(97)00306-2

51 Cranney A, Feibel R, Toye BW, Karsh J. Osteomyelitis subsequent to abdominal-vaginal sacropexy. J Rheumatol. 1994;21(09): $1769-1770$

52 Cailleux N, Daragon A, Laine F, Deshayes P, Le Loët X, Duval C. [Infectious spondylodiscitis after a cure for genital prolapse. 5 cases]. J Gynecol Obstet Biol Reprod (Paris). 1991;20(08): 1074-1078

53 Wagner L, Meurette G, Vidart A, Warembourg S, Terassa J-B, Berrogain N, et al. [Laparoscopic sacrocolpopexy for pelvic organ prolapse: guidelines for clinical practice]. Prog Urol. 2016;26 (Suppl 1):S27-S37. Doi: 10.1016/S1166-7087(16)30426-2

54 Good MM, Abele TA, Balgobin S, Schaffer JI, Slocum P, McIntire D, et al. Preventing L5-S1 discitis associated with sacrocolpopexy. Obstet Gynecol. 2013;121(2 Pt 1):285-290. Doi: 10.1097/AOG.0b013e31827c61de 